\title{
Forensic age assessment using Kvaal's method with digital orthopantomographs (OPG) and comparison with the actual age of the subjects
}

\author{
Azia Manzoor ${ }^{1}$, Vinka Maini' $^{2}$, Wasim Manzoor ${ }^{3}$ \\ ${ }^{1}$ Assistant Professor and I/C Head, Department of Forensic Medicine and Toxicology, Government Medical College \\ Anantnag, JK, '2Lecturer, Department of Forensic Medicine and Toxicology, Government medical college Jammu, JK, \\ ${ }^{3}$ Senior Resident, Department of Dentistry, SKIMS Soura, Srinagar, JK
}

Background: Forensic Dentistry is one of the branch of Forensic Medicine which deals with the complete handling of dental evidence, estimation and examination and the evidence obtained would be used in the court for justice. Kvaal and Solheim given a method used on adults for calculation of age with the help of morphological and radiological methods, but extraction was still required. Hence to improve this procedure Kvaal et al made a method which is totally based on radiological analysis. Aims and Objective: The present study was designed to compare the forensic age assessment using Kvaal's method and digital orthopantomographs with the actual age of the subjects. Materials and Methods: Present observational study was conducted in subjects with all the required complement of teeth on either right or left side, completely erupted clinical crown, without any morphological abnormalities for age estimation by Kvaal's method with digital orthopantomograph as and compared with actual age of subjects. Results: In the present study out of 100 subjects, maximum number of subjects i.e. 61 were in the age group of $20-29$ and minimum number of subjects i.e. 7 were in the age group of $50-59.43$ were females and 57 were males. The regression equation was derived for all six studied teeth and coefficient of determination $\mathrm{R}^{2}$ was found for all the individual six teeth. Coefficient of determination was highest for lower first premolar (0.517) followed by upper central incisor (0.178), lower canine (0.134), lower lateral incisors, upper second premolar and upper lateral incisors. M \& W-L were found significant predictors for lower first premolar, lower canine and upper central incisors. Similarly, coefficient of determination $\left(R^{2}\right)$ was significant higher for lower three teeth (0.478) than upper three teeth (0.069) with $M$ \& W-L were significant predictor. Regression equation derived for all six teeth together shows significant coefficient of determination $\mathrm{R}^{2}(0.430)$ with $\mathrm{M}, \mathrm{W}$-L both are significant predictors. No statistically significant difference between the actual age and estimated age for all individual six teeth was noted. Mean difference lowest for lower first premolar (0.001) followed by lower canine (0.007). Conclusion: We noted that age assessment using Kvaal's method with digital orthopantomographas and actual age of the subjects were comparable \& no significant difference was noted. Kvaal's method with digital orthopantomographas is a better option for age estimation without teeth removal.

Key words: Forensic dentistry; Kvaal's method; Digital orthopantomographs (OPG); Age estimation

\section{Access this article online}

Website:

http://nepjol.info/index.php/AJMS DOI: $10.3126 /$ ajms.v12i10.38349

E-ISSN: 2091-0576

P-ISSN: 2467-9100

Copyright (c) 2021 Asian Journal of Medical Sciences

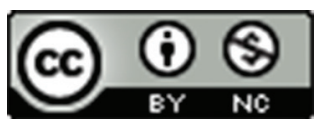

This work is licensed under a Creative Commons Attribution-NonCommercial 4.0 International License. 


\section{INTRODUCTION}

Forensic Medicine played important role in establishing the identity of a person whether living or dead or whether the person is murdered, drowned, burned and his body is destroyed beyond recognition. ${ }^{1}$

Forensic Dentistry is one of the branch of Forensic Medicine which deals with the complete handling of dental evidence, estimation and examination and the evidence obtained would be used in the court for justice. ${ }^{2}$ Dental evidence can be used to assess the age and identify the identity of the individual to whom the teeth belong. The work of a Forensic Odontologist are as to identify the bite marks, to produce dental evidence in the court by comparing the teeth of the suspect with the bite marks, age calculation of the remains of the skeleton. ${ }^{3,4}$

Even when bones and all the other tissues of the body have break down then also the teeth become firmest to calculate the age of an individual. Most commonly used morphological procedures depend on the length of apical translucent zone, secondary dentin, attrition, root resorption, periodontal attachment and cementum apposition. But these procedures need removal of teeth and are very time consuming and expensive. ${ }^{5}$

Kvaal and Solheim given a method used on adults for calculation of age with the help of morphological and radiological methods, but extraction was still required. Hence to improve this procedure Kvaal et al., made a method which is totally based on radiological analysis. ${ }^{6}$ Bosmans et al., modified the original Kvaal et al., technique, which used individual periapical $\mathrm{X}$ rays could be applied to digital OPG's(orthopantomogram) taken. ${ }^{7}$ In present study we compared forensic age assessment using Kvaal's method and digital orthopantomographs with the actual age of the subjects.

\section{MATERIALS AND METHODS}

The present observational study was conducted in Forensic Medicine Department of MMIMSR, Mullana and Oral Medicine and Radiology Department of MMCDSR, Mullana, Ambala. Study duration was period was 18 months (from November 2014 to April 2016). Ethical committee approval was taken before embarking this study.

The Inclusion criteria for the study subjects were:

- Subjects with all the required complement of teeth on either right or left side, completely erupted clinical crown, without any morphological abnormalities

- Have an authenticated proof of date of birth

\section{Exclusion criteria}

- Subjects with any one of the six required teeth missing or impacted.

- Subjects with systemic disorders like renal/liver/heart diseases, blood dyscrasias,

- Subjects who failed to produce authenticated date of birth proof.

- Also the teeth involved for the study were: carious/ restored either in the crown or root or have prosthesis to it/have pulp stones or pulpal pathologies/malposed teeth/teeth with wasting diseases (attrition/abrasion/ erosion)

Randomly 100 cases were selected. The subjects were explained about the details of the study and the procedure in the language understandable to them.

The subjects were made to sit comfortably on the physiological dental chair and a thorough planned detailed case history was taken in the preformed case sheet. A thorough clinical examination was carried out on the subjects under suitable set up, and absolute aseptic conditions under sufficient illumination. Measurements were performed on the digital panoramic radiograph on six teeth i.e. maxillary central incisor, maxillary lateral incisor, maxillary second premolar, mandibular lateral incisor, mandibular canine and mandibular first premolar. The measurements were carried out on the orthopantomographs for all six types of teeth using dimaxis digital software.

Age was assessed for all the subjects by regression using two predictors, where "M" was the first predictor and "WL" was the second predictor. The correlation between age and the ratios of measurement from each tooth i.e. ratio between pulp length and root length $(\mathrm{P})$, ratio between root length and tooth length $(\mathrm{T})$, ratio between pulp length and tooth length $(\mathrm{R})$, ratio between width of pulp and width of root at the level of cementoenamel junction or level a (A), ratio between width of pulp and width of root at the midpoint between cemento-enamel junction and mid root level i.e. level $b(B)$, ratio between width of pulp and width of root at the mid root level or level c (C), mean value of all ratios $(\mathrm{M})$, mean value of width ratios from level $b$ and $c(W)$, mean value of length ratios 'P' and 'R' (L), and difference between 'W' and 'L' (W-L).

Regression formulae based on statistical analysis were calculated using and different regression formulae for all six teeth, three maxillary teeth only, three mandibular teeth only and each individual tooth were derived and age was assessed, the assessed age was then co-related with the actual age of the patient. The entire results were presented in the form of tables and graphs. 
The age for each of the subjects was calculated using these regression equations and compared with the actual age using the student's t- test. $\mathrm{p}$ value less than 0.05 was considered as statistically significant.

\section{RESULTS}

In the present study out of 100 subjects, maximum number of subjects i.e. 61 were in the age group of 20-29 and minimum number of subjects i.e., 7 were in the age group of 50-59. Forty-three were females and 57 were males (Table 1).

The regression equation was derived for all six studied teeth and coefficient of determination $\mathrm{R}^{2}$ was found for all the individual six teeth (Table 2). Coefficient of determination was highest for lower first premolar $(0.517)$ followed by upper central incisor (0.178), lower canine (0.134), lower lateral incisors, upper second premolar and upper lateral incisors. M \& W-L were found significant predictors for lower first premolar, lower canine and upper central incisors. Similarly, coefficient of determination $\left(\mathrm{R}^{2}\right)$ was significant higher for lower three teeth (0.478) than upper three teeth (0.069) with M \& W-L were significant predictor. Regression equation derived for all six teeth together shows significant coefficient of determination $\mathrm{R}^{2}(0.430)$ with $\mathrm{M}$, W-L both are significant predictors (Table 3 ).

No statistically significant difference between the actual age and estimated age for all individual six teeth was noted. Mean difference lowest for lower first premolar(0.001) followed by lower canine (0.007).

\begin{tabular}{|c|c|c|c|}
\hline \multirow[t]{2}{*}{ Age Group } & \multicolumn{2}{|c|}{ Sex } & \multirow[t]{2}{*}{ Tota } \\
\hline & Female & Male & \\
\hline $20-29$ & 26 & 35 & 61 \\
\hline $30-39$ & 10 & 6 & 16 \\
\hline $40-49$ & 5 & 11 & 16 \\
\hline $50-59$ & 2 & 5 & 7 \\
\hline Total & 43 & 57 & 100 \\
\hline
\end{tabular}

\section{DISCUSSION}

Dental identification of humans is important for a number of different reasons and in number of different situations. Sometimes the identification by the victim family is not possible or reliable because of the fires, violent crimes, acid on the victim, road accidents, bomb blasts. Person obtained from water also become disfigured that identification is difficult or impossible. Identification by dentine always have important role in mass causalities where fingerprinting is not possible. ${ }^{4}$

Gustafson, provided the first scientific method of age estimation based on morphological and histological changes of the teeth, which employed six individual agerelated changes but did not include difference in color or fluorescence from any tooth structure. ${ }^{8}$ Johansson modified Gustafson technique by using more detailed scale and by multiple regression analysis. But both these techniques employ destruction of the tooth specimen. ${ }^{\text {? }}$

Kvaal et al., ${ }^{10}$ outlined a technique for estimating an age from dental radiographs based on the amount of secondary dentin. Six teeth are assessed from right or left side. Pulp width was measured at three different levels of the root: at the level of enamel-cemento junction (ECJ), Between the ECJ and the root apex and at the mid-point between the ECJ and mid root level. He stated that the level of secondary dentin deposited can be representative of individual age and observe that co efficient was highest when the age estimation standard for all six teeth was applied (0.76), the standard error of the age estimation was reported to be 8.6 years. Later it was also suggested that the technique can be applied to full mouth radiographs or orthopantomograms (OPG), although the author did not provide any quantitative assessment.

Paewinsky et al., used Kvaal age estimation standards in 168 individuals age between 14 to 81 years was done. Using a logistic regression model, the co-efficient of determination was found to be highest for the upper lateral incisors. Their regression model had a standard error of

Table 2: Regression analysis for lower three teeth

\begin{tabular}{|c|c|c|c|}
\hline Teeth & Equation & $\mathbf{R}^{2}$ & $\begin{array}{l}\text { Significant } \\
\text { Predictors }\end{array}$ \\
\hline Lower canine & Age $=46.86-76.31 \mathrm{M}-33.57 \mathrm{~W}-\mathrm{L}$ & 0.134 & $M \& W-L$ \\
\hline Lower Lateral Incisor & Age $=-11.23+132.83 \mathrm{M}+31.76 \mathrm{~W}-\mathrm{L}$ & 0.057 & NONE \\
\hline Lower first Premolar & Age $=53.47-126.145 \mathrm{M}-63.98 \mathrm{~W}-\mathrm{L}$ & 0.517 & $M \& W-L$ \\
\hline Upper Second premolar & Age $=43.62-102.66 \mathrm{M}-55.46 \mathrm{~W}-\mathrm{L}$ & 0.044 & $\mathrm{M}$ \\
\hline Upper lateral incisor & Age $=41.08-9.72 \mathrm{M}+5.38 \mathrm{~W}-\mathrm{L}$ & 0.033 & NONE \\
\hline Upper central incisor & Age $=41.84-130.96 \mathrm{M}-78.64 \mathrm{~W}-\mathrm{L}$ & 0.178 & $M \& W-L$ \\
\hline Lower three teeth & Age $=42.84-216.2 \mathrm{M}-128.78 \mathrm{~W}-\mathrm{L}$ & 0.478 & $M \& W-L$ \\
\hline All Six teeth & Age $=57.97-343.47 \mathrm{M}-194.34 \mathrm{~W}-\mathrm{L}$ & 0.430 & $M \& W-L$ \\
\hline
\end{tabular}




\begin{tabular}{|c|c|c|c|c|c|c|c|}
\hline \multirow[t]{2}{*}{ Tooth } & \multicolumn{2}{|c|}{ Actual age } & \multicolumn{2}{|c|}{ Estimated age } & \multirow[t]{2}{*}{ Mean difference } & \multirow[t]{2}{*}{$\mathbf{t}$} & \multirow[t]{2}{*}{ p-value } \\
\hline & Mean & SD & Mean & SD & & & \\
\hline Upper Second premolar & 31.19 & 10.39 & 31.13 & 2.17 & 0.060 & -0.003 & 0.998 \\
\hline Upper lateral incisor & 31.19 & 10.39 & 31.15 & 1.88 & 0.044 & 0.043 & 0.966 \\
\hline Upper central incisor & 31.19 & 10.39 & 31.29 & 4.35 & -0.099 & -0.105 & 0.917 \\
\hline Lower canine & 31.19 & 10.39 & 31.18 & 3.82 & 0.007 & 0.007 & 0.994 \\
\hline Lower Lateral Incisor & 31.19 & 10.39 & 31.22 & 2.48 & -0.029 & -0.029 & 0.977 \\
\hline Lower first Premolar & 31.19 & 10.39 & 31.18 & 7.40 & 0.001 & 0.001 & 0.999 \\
\hline Upper three teeth & 31.19 & 10.39 & 31.18 & 2.74 & 0.002 & 0.002 & 0.998 \\
\hline Lower three teeth & 31.19 & 10.39 & 31.21 & 7.14 & -0.019 & -0.025 & 0.980 \\
\hline All Six teeth & 31.19 & 10.39 & 31.18 & 6.81 & 0.007 & 0.007 & 0.994 \\
\hline
\end{tabular}

6.68 years. The authors concluded that the original Kvaal et al., ${ }^{10}$ age estimation can be reliably applied to German population and a strong correlation existed between age and the pulp size. ${ }^{11}$

A Panoramic radiograph or OPG is an extra oral diagnostic single image which shows the upper and lower dental arches, teeth, temporomandibular joints and its surrounding structures. ${ }^{12,13}$ Hegde RJ ${ }^{14}$ conducted a study from OPG with the help of Demirjian methods and to check the suitability of Demirjian procedure for age estimation. They noted the mean difference between the true age and assessed age for females found over estimation of ( 0.04 years) 15 days and in males over estimation of ( 0.14 years) 51 days.

Ridhima Sharma, Anurag Srivastva conducted a study to calculate the age of individual with the help of Kvaal's procedure with OPG. Noticeable variation was observed in the maxillary lateral incisors and mandibular lateral incisors. In the end the present study shows the excellent capability of Kvaal's method in set sample. ${ }^{15}$

Samta Mittal, Suma Gundareddy et al., ${ }^{16}$ applied Kvaals technique of age estimation in the Indian population using simple tools like digital imaging on living individuals not requiring extraction of teeth and observed that no significant difference between the mean of the chronological age and the estimated age. They concluded that the results of the study give an inference for the feasibility of this technique by calculation of regression equations on digital panoramic radiographs.

In our study, we have used digital orthopantomographs for assessment of age, whereas study by Kvaal et al., ${ }^{10}$ used the intraoral periapical radiographs and Nathalie Bosman et $\mathrm{al}^{6}$ used orthopantomographs for obtaining the regression formula. Orthopantomographs were selected in this study because of the possibility of the evaluation of all teeth along with alveolar bone in both jaws, several measurements can be performed on the same x-rays. Furthermore, orthopantomograph is a standard technique with high reproducibility, while the acceptability of intraoral radiographs is dependent on the techniques used and the practical training of the personnel. Present study was a small sample study, larger studies with broader inclusion criteria are needed for larger application.

Kvaal's method with digital orthopantomographas is a noninvasive method of age estimation (without teeth removal), will help in Forensic dentistry for age estimation.

\section{CONCLUSION}

We noted that age assessment using Kvaal's method with digital orthopantomographas and actual age of the subjects were comparable \& no significant difference was noted. Kvaal's method with digital orthopantomographas is a better option for age estimation without teeth removal.

\section{Acknowledgement}

The authors take this opportunity to thank Department of Radiology and Surgery for their whole hearted support for this study.

\section{REFERENCES}

1. Singh A. Age estimation from physiological changes of teeth. Journal of Indian Academy of Forensic Medicine. 2004; 26 (3): 0971-0973.

2. Seth S. Determination of age from teeth using index value of attrition. Internet Journal of forensic medicine and toxicology. 2003; 1 (2): 1-2.

3. Acharya AB. Teaching forensic odontology: an opinion on its content and format. European Journal of dental education. 2006; 10 (3):137-141.

https://doi.org/10.1111/j.1600-0579.2006.00405.x

4. Pretty A and Sweet D. A look at forensic dentistry part I: the role of teeth in the determination of human identity. Br Dent J. 2001; 190 (7): 359-366.

https://doi.org/10.1038/sj.bdj.4800972

5. Rai B, Dhattarwal SK and Anand SC. Five Markers of Changes in Teeth: An Estimating of Age. The Internet Journal of Forensic Science. 2006; 1 (2):130-132. 
https://doi.org/10.5580/281a

6. Kvaal SI and Solheim T. Incremental lines in human dental cementum in relation to age. European Journal of oral Science. 1995;103 (4): 225-230.

https://doi.org/10.1111/j.1600-0722.1995.tb00164.x

7. Bosman N, Ann P and Willems G. The application of Kvaal's dental age calculation technique on panoramic dental radiographs. Forensic Science International.2005; 153 (2-3): 208-212.

https://doi.org/10.1016/j.forsciint.2004.08.017

8. Gustafson G. Age determination on tooth. Journal of American Dental Association. 1950; 41(1): 45-54.

https://doi.org/10.14219/jada.archive.1950.0132

9. Johanson G. Age Determination from Human Teeth. Odontological Review. 1971; 22(21): 1-126.

10. Kvaal SI, Koltveit KM, Thomsen $I O$ and Solheim T. Age estimation of adults from dental radiographs. Foresnsic Science International.1995; 74:175-185.

https://doi.org/10.1016/0379-0738(95)01760-G

11. Paewinsky E. Quantification of secondary dentine formation from orthopantomograms-a contribution to forensic age estimation methods in adults. International Journal of Legal Medicine. 2005; 119(1): 27-30.

https://doi.org/10.1007/s00414-004-0492-x

12. Chiam SL. A note on digital dental radiography in forensic odontology. Journal of Forensic Dentistry Science. 2014; 6(3): 197-201.

13. Monsour PA. Getting the most from rational panoramic radiograph.Australian Dental Journal. 2000; 45 (2):136-142. https://doi.org/10.1111/j.1834-7819.2000.tb00254.x

14. Hegde RJ and Sood PB. Dental maturity as an indicator of chronological age: radiographic evaluation of dental age in 6 to 13 years children of Belgaum using Demirjian methods. Journal of Indian Society of Pedodontic and Preventive Dentistry. 2002; 20 (4): $132-138$.

15. Sharma $R$ and Srivastava A. Radiographic evaluation of dental age of adults using Kvaal'smethod. Journal of dental Sciences.2015;2(1):22-26. https://doi.org/10.4103/0974-2948.71053

16. Mittal S, Gundareddy S and Sharma ML. Age estimation based on Kvaal's technique using digital panoramic radiographs. Journal of Forensic Dental Science. 2016; 8 (2):115. https://doi.org/10.4103/0975-1475.186378

\section{Author's contribution:}

VM-Concept and design of the study; coordination, review of literature, prepared first draft of manuscript; WM-Interpreted the results; reviewed the literature and manuscript preparation; AM-Statistically analyzed and interpreted, preparation of manuscript and revision of the manuscript.

\section{Work attributed to:}

Government medical college Jammu, JK, India.

Orcid ID:

Dr Vinka Maini- (D) https://orcid.org/0000-0002-4612-0089

Source of Funding: None, Conflict of Interest: None. 